\title{
DETECTION AND IDENTIFICATION OF LEISHMANIA SPECIES WITHIN NATURALLY INFECTED SAND FLIES IN THE ANDEAN AREAS OF ECUADOR BY A POLYMERASE CHAIN REACTION
}

\author{
HIROTOMO KATO, HIROSHI UEZATO, KEN KATAKURA, MANUEL CALVOPIÑA, JORGE D. MARCO, \\ PAOLA A. BARROSO, EDUARDO A. GOMEZ, TATSUYUKI MIMORI, MASATAKA KORENAGA, HIROYUKI IWATA, \\ SHIGEO NONAKA, AND YOSHIHISA HASHIGUCHI \\ Department of Veterinary Hygiene, Faculty of Agriculture, Yamaguchi University, Yamaguchi, Japan; Department of Dermatology, \\ Faculty of Medicine, University of the Ryukyus, Okinawa, Japan; Laboratory of Parasitology, Department of Disease Control, \\ Graduate School of Veterinary Medicine, Hokkaido University, Sapporo, Japan; Department of Parasitology, Kochi Medical School, \\ Kochi University, Kochi, Japan; Departamento de Medicina Tropical, Facultad de Medicina, Universidad Catolica de Guayaquil, \\ Guayaquil, Ecuador; Department of Tumor Genetics and Biology, Graduate School of Medical Science, Kumamoto University, \\ Kumamoto, Japan
}

\begin{abstract}
The surveillance of prevalent Leishmania and sand fly species in endemic areas is important for prediction of the risk and expansion of leishmaniasis. In this study, we developed a polymerase chain reaction (PCR)-based method for detection of Leishmania minicircle DNA within individual sand flies. Using this method, we detected minicircle DNA in $6(3.3 \%)$ of 183 sand flies, while $5(3.5 \%)$ of 143 were positive for Leishmania promastigotes in the same areas by microscopic examination. The species were identified as Leishmania (Leishmania) mexicana by nucleotide sequencing of the cytochrome b gene. Additionally, all the Leishmania-positive sand flies were identified as Lutzomyia ayacuchensis by the restriction enzyme digestion of the PCR-amplified 18S ribosomal RNA gene fragments. Since this combined method is relatively easy and can process a large number of samples, it will be a powerful tool for the rapid identification of prevalent sand fly and Leishmania species as well as monitoring the infection rate in sand fly populations in endemic areas.
\end{abstract}

\section{INTRODUCTION}

Leishmaniasis is a protozoan disease caused by the genus Leishmania. It is distributed worldwide, especially in tropical and subtropical areas, and affects at least 12 million people. ${ }^{1,2}$ More than 20 species of Leishmania have been described as causative agents of human leishmaniases and clinical features are largely associated with the Leishmania species. ${ }^{1,2}$ Identi- $^{-}$ fication of the parasite species in endemic areas is important for both appropriate treatment and estimation of the patient's prognosis. Leishmania protozoa are transmitted by female sand flies of the genus Phlebotomus in the Old World and Lutzomyia in the New World. ${ }^{3}$ The spread of leishmaniases depends on the distribution of the vectors and reservoir animals. There are more than 500 sand fly species, only a few of which are medically important. ${ }^{3}$ In addition, it has been suggested that restricted sand fly species can support the development of specific species of Leishmania and consequently transmit certain ones. ${ }^{3}$ Thus, the detection and identification of Leishmania species within naturally infected sand flies is important for prediction of the risk and expansion of the disease in endemic areas.

The infection of sand flies with Leishmania promastigotes has usually been examined by the dissection of individual sand flies by microscopy. For this purpose, sand flies should be fresh and a procedure requiring considerable skill and expertise is needed for the dissection of tiny sand flies. However, this procedure takes a relatively long time to perform and is not suitable for the examination of a large number of sand flies. Furthermore, for identification of the Leishmania species within sand flies, the isolation of parasites in culture without bacterial and/or fungal contamination is required for each dissected sand fly sample and isolated parasites are required for further zymodeme, ${ }^{4}$ serodeme, ${ }^{5,6}$ schizodeme $^{7}$ karyotype, ${ }^{8}$ or polymerase chain reaction $(\mathrm{PCR})^{9-22}$ analysis. A recent study showed that Leishmania species within sand flies were successfully detected and identified in the Old
World by a two-step PCR method targeting minicircle kinetoplast DNA. ${ }^{23}$

Since 1982, we have conducted epidemiologic research on leishmaniases in the New World, especially in Ecuador. ${ }^{24-27}$ In our studies, we have shown that two species, L. (Leishmania) mexicana and L. (L.) major-like, were involved in Andean cutaneous leishmaniasis in Ecuador, and only Lutzomyia (Lu) ayacuchensis was considered to transmit these parasites although other sand fly species existed as minor populations in the endemic area. ${ }^{28-30}$ Furthermore, the infection rate of sand flies with Leishmania protozoa in these regions was higher in the Andean regions than in lowland areas. ${ }^{28-30}$ Our goal, using only Lutzomyia ayacuchensis, was to develop a simple method for the identification of both Leishmania and sand fly species using molecular biologic techniques including a PCR and restriction enzyme digestion of the PCR products.

In the present study, we detected Leishmania DNA within ethanol-fixed individual sand flies captured in areas of Ecuador where cutaneous leishmaniasis is endemic by PCR amplification of minicircle kinetoplast DNA. The Leishmania species were determined by PCR amplification and sequencing of the cytochrome b ( Cyt b) gene. ${ }^{31}$ Furthermore, the sand fly species were identified by additional PCR amplification of the $18 \mathrm{~S}$ ribosomal RNA (rRNA) genes and digestion with a restriction enzyme. This method will be a powerful tool not only for mass screening of the infection rate of Leishmania in sand fly populations, but also for the rapid identification of prevalent Leishmania and sand fly species in areas endemic for leishmaniasis.

\section{MATERIALS AND METHODS}

Parasites. Five World Health Organization reference strains of Leishmania, L. (L.) mexicana (MNYC/BZ/62/M379), L. (Viannia) panamensis (MHOM/PA/71/LS94), L. (V.) guyanensis (MHOM/BR/75/M4147), L. (L.) major-like (MHOM/ EC/88/PT-115), and L. (V.) braziliensis (MHOM/BR/75/ 
M2904), were cultured in RPMI 1640 medium (Nissui Pharmaceuticals, Tokyo, Japan) supplemented with $10 \%$ fetal calf serum (Cansera International, Etobicoke Ontario, Canada), $2 \mathrm{mM}$ L-glutamine, $100 \mathrm{units} / \mathrm{mL}$ of penicillin, and $100 \mu \mathrm{g} / \mathrm{mL}$ of streptomycin at $25^{\circ} \mathrm{C}$.

Sand fly collection. Sand flies were caught in two Andean areas in Ecuador, Chanchan and Alausi, Province of Chimborazo, where Andean-type cutaneous leishmaniasis caused by $L$. (L.) mexicana and $L$. (L.) major-like is prevalent. ${ }^{28-30}$ The collected sand flies were dissected and then identified at the species level based on the morphology of their spermathecae. These flies were also examined for Leishmania promastigotes by microscopy. Some of the Leishmania-positive and -negative flies dissected were processed for analysis by the PCR. Conversely, intact sand flies were individually fixed in $70 \%$ ethanol and stored for further analysis to obtain the natural infection rate of sand flies with Leishmania parasites in the study area. In a separate experiment, sand flies were also captured in lowland subtropical areas (Puerto Quito, Province of Pichincha and La Troncal, Province of Cañar) where cutaneous leishmaniasis caused by $L$. (V.) panamensis and $L$. (V.) guyanensis is dominant. These flies were also dissected and identified at the species level based on morphology, and fixed individually in $70 \%$ ethanol; the samples were used in the control study for classification of sand fly species using the present molecular technique, but not used for other purposes in this study.

Extraction of DNA. Ethanol-fixed individual sand flies were homogenized and lysed in DNA extraction buffer $(150$ $\mathrm{mM} \mathrm{NaCl}, 10 \mathrm{mM}$ Tris- $\mathrm{HCl}, \mathrm{pH}$ 8.0, $10 \mathrm{mM}$ EDTA, 0.1\% sodium dodecyl sulfate) with $100 \mu \mathrm{g} / \mathrm{mL}$ of proteinase $\mathrm{K}$ at $37^{\circ} \mathrm{C}$ for 12 hours. These samples were then extracted with phenol and chloroform followed by precipitation with ethanol. The DNA pellets were resuspended in $10 \mu \mathrm{L}$ of distilled water and $1-\mu \mathrm{L}$ portions of these DNA extracts were subjected to PCR amplification.

Polymerase chain reaction amplification. The PCR primers were designed based on the Leishmania minicircle kinetoplast DNA sequences conserved among species. The primer sequences used for amplification were 5' -CTRGGGGTTGGTGTAAAATAG-3' (L.MC-1S) and 5'-TWTGAACGGGRTTTCTG-3' (L.MC-1R). The reaction was carried out in a volume of $25 \mu \mathrm{L}$ using a pair of primers $(0.4 \mu \mathrm{M}$ each) and $2 \times$ PCR solution (Premix Taq; Takara Bio, Shiga, Japan). After an initial denaturation at $95^{\circ} \mathrm{C}$ for two minutes, the PCR amplification with Leishmania minicircle kinetoplast DNAspecific primers was performed with 30 cycles of denaturation ( $95^{\circ} \mathrm{C}$ for one minute), annealing $\left(55^{\circ} \mathrm{C}\right.$ for one minute), and polymerization $\left(72^{\circ} \mathrm{C}\right.$ for one minute), followed by a final extension at $72^{\circ} \mathrm{C}$ for 10 minutes.

As a positive control for DNA extraction, PCR amplification was also performed with a pair of primers specific for sand fly DNA. The primers were designed based on the Lutzomyia $18 \mathrm{~S}$ rRNA gene sequences conserved among species. The primer sequences used were 5'-TGCCAGTAGTTATATGCTTG-3' (Lu. 18S rRNA-1S) and 5'-TTACGCGCCTGCTGCCTTCC-3' (Lu. 18S rRNA-1R). The PCR amplification was performed under the same condition as described earlier in this report.

For the identification of Leishmania species by a molecular biologic method, PCR amplification was performed with primers specific for the Leishmania Cyt b gene. ${ }^{31}$ The primer sequences used were 5'-GGTGTAGGTTTTAGTYTAGG3' (L.cyt-S) and 5'-CTACAATAAACAAATCATAATATRCAATT-3' (L.cyt-R). The conditions used for PCR amplification were the same as described earlier in this report.

Molecular cloning and nucleotide sequencing. The PCR products were analyzed by electrophoresis on $2 \%$ agarose gels and then directly cloned into a plasmid using the pGEM-T Easy Vector System (Promega, Madison, WI). Escherichia coli XL-1 blue cells were transformed with the ligation mixture and plated onto Luria Bertani agar plates containing ampicillin $(50 \mu \mathrm{g} / \mathrm{mL})$, 5-bromo-4-chloro-3-indolyl $\beta$-D-galactoside $(36 \mu \mathrm{g} / \mathrm{mL})$, and isopropyl $\beta$-D-thiogalactoside $(40 \mu \mathrm{g} / \mathrm{ml})$. Plasmid DNAs were extracted with a QIAprep Spin Miniprep Kit (Qiagen, Valencia, CA). The inserts of the plasmids were sequenced by the dideoxy chain termination method using a BigDye Terminator version 3.1 Cycle Sequencing Kit (Applied Biosystems, Foster City, CA).

\section{RESULTS}

Morphologic identification of sand flies. In our epidemiologic survey, we have reported that the vector sand flies caught in two Andean areas (Chanchan and Alausi) were a unique species (Lu. ayacuchensis). ${ }^{28}$ In the present study, we randomly divided the sand flies captured in Chanchan and Alausi into two groups: one (105 and 38 flies, respectively) was used for microscopic examination and the other (115 and 68 flies, respectively) was used for the establishment of a PCR-based detection method for Leishmania parasites. We dissected 105 and 38 sand flies captured in Chanchan and Alausi, respectively, and examined the species based on the morphology of their spermathecae. As a result, we found that all the sand flies examined were Lu. ayacuchensis, corresponding to our previous findings. ${ }^{28}$

Sensitivity of the PCR assay. To establish a detection system for Leishmania DNA, we tested the specificity and sensitivity of our PCR method with primers specific for Leishmania minicircle kinetoplast DNA. We used as templates genomic DNA equivalent to 10,1 , or 0.1 parasites from five reference strains of Leishmania species distributed in Ecuador. As shown in Figure 1, we could amplify minicircle kinetoplast DNA from all the Leishmania species examined and could detect $0.1-1$ parasites in these species. The sensitivity is high enough to detect Leishmania promastigotes within individual sand flies. We confirmed that these amplified fragments were actually minicircle kinetoplast DNAs using a

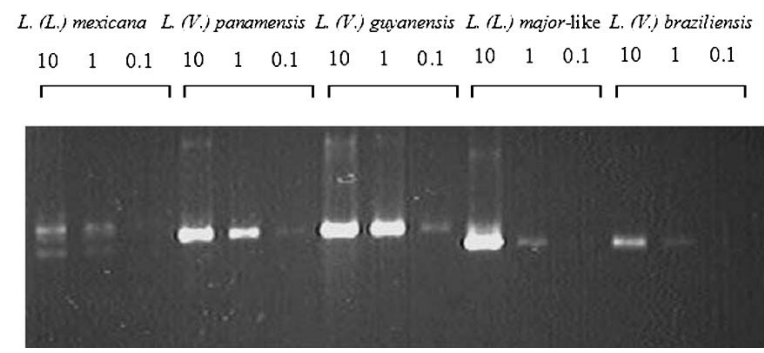

FIGURE 1 . Specificity and sensitivity of a polymerase chain reaction with primers specific for Leishmania minicircle kinetoplast DNA. Genomic DNA equivalent to 10,1 , or 0.1 parasites from the five reference Leishmania species $L$. (L.) mexicana, $L$. (V.) panamensis, L. (V.) guyanensis, L. (L.) major-like, and L. (V.) braziliensis, were used as templates. 
PCR-Southern blotting method with L. (L.) mexicana minicircle kinetoplast DNA probe and nucleotide sequencing of the PCR products.

Molecular cloning and sequencing of sand fly $18 S$ rRNA genes. We designed a pair of primers based on reported conserved sequences of the Lutzomyia $18 \mathrm{~S}$ rRNA gene. In addition to DNA from Lu. ayacuchensis, we also used DNA samples from other sand fly species such as Lu. hartmanni, Lu. trapidoi, Lu. panamensis, and Lu. gomezi as templates to assess if 18S rRNA genes of other species can be amplified with the primers used. Electrophoresis of each PCR product gave a single DNA band with an expected size of approximately 450 basepairs in all samples. The nucleotide sequences of these DNA fragments showed that all were a part of the 18S rRNA gene of Lutzomyia species judging from homology with counterparts of Lu. geniculata, Lu. longipalpis, Lu. nunez-tovari anglesi, Lu. toroensis, Lu. vattieri, and Lu. verrucarum (95.8-99.3\%) (Figure 2). Thus, the primers designed in this study were shown to react with $18 \mathrm{~S}$ rRNA genes from a wide variety of sand fly species.

Detection of Leishmania and Lutzomyia DNA from individual ethanol-fixed sand flies by PCR. We dissected 105 and
38 sand flies captured in Chanchan and Alausi, respectively, and examined them for Leishmania promastigotes within their gut by microscopy. Two of 105 flies $(1.9 \%)$ from Chanchan and 3 of 38 flies $(7.9 \%)$ from Alausi were positive for Leishmania promastigotes in the foregut and midgut (Table 1).

For detection of Leishmania and Lutzomyia DNA, we performed a PCR using Leishmania minicircle kinetoplast DNAspecific and sand fly $18 \mathrm{~S}$ rRNA gene-specific primers in microscopically ascertained Leishmania-positive or -negative sand fly samples. A distinct DNA band of apptoximately 700 basepairs corresponding to minicircle kinetoplast DNA was detected in a Leishmania-positive sand fly sample (Figure 3, lane 1) but not in a negative one (Figure 3, lane 3), although sand fly $18 \mathrm{~S}$ rRNA genes were detected in both samples (Figure 3 , lanes 2 and 4 ). In additional trials, to avoid any chance of contamination among samples at material collections, DNAs were extracted from the other group of individual intact sand flies without dissection (destruction) and subjected to PCR analysis for the detection of Leishmania parasites as described earlier. Using this method, we found that 2 of 115 flies $(1.7 \%)$ from Chanchan and 4 of 68 flies $(5.9 \%)$ from Alausi were positive for Leishmania DNA (Table 1). These

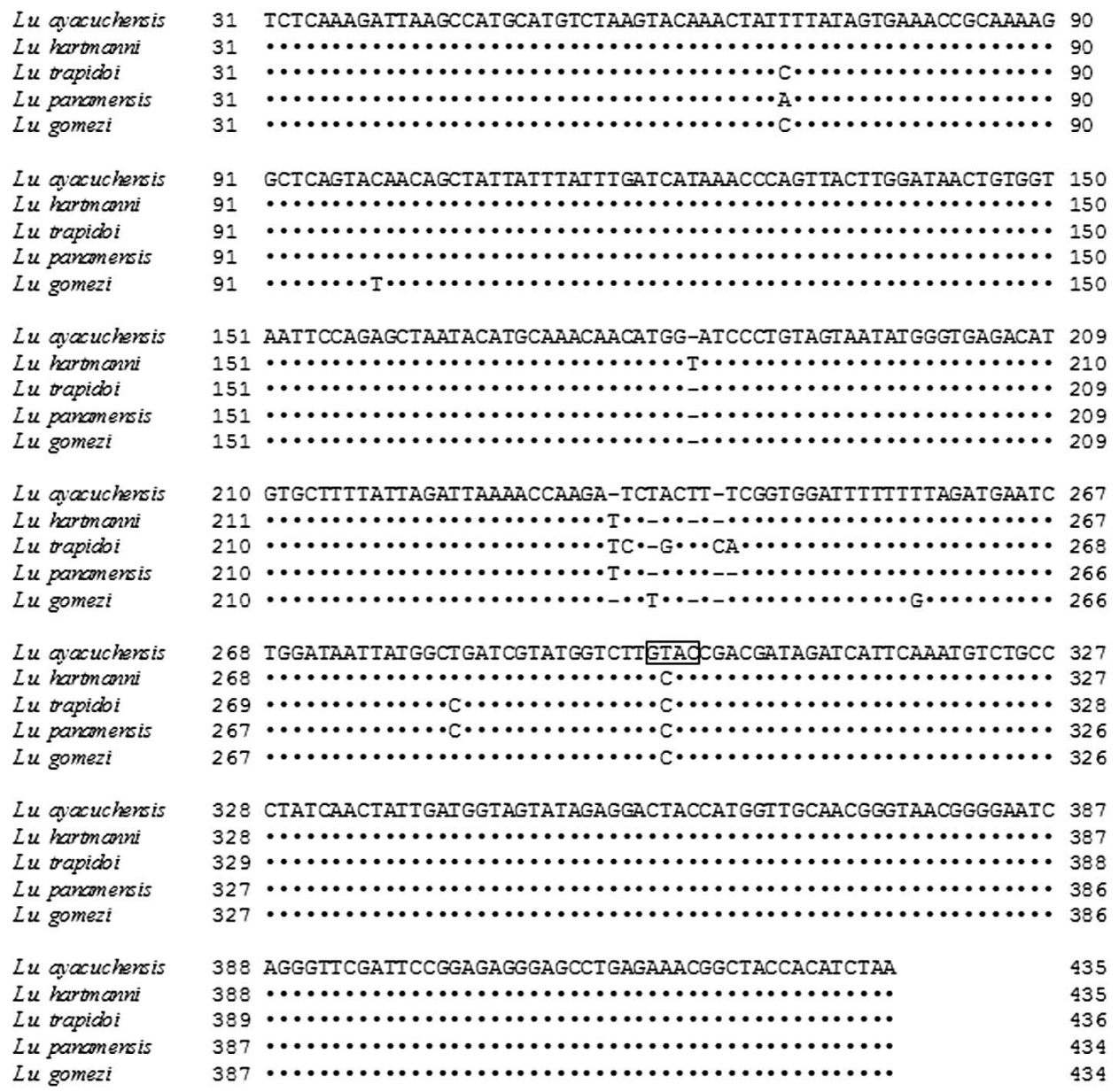

FIGURE 2. Comparison of partial $18 \mathrm{~S}$ ribosomal RNA (rRNA) gene sequences of different Lutzomyia species. The nucleotide sequence of the $18 \mathrm{~S}$ rRNA gene from Lutzomyia ayacuchensis is aligned with sequences from Lu. hartmanni, Lu. trapidoi, Lu. panamensis, and Lu. gomezi. Nucleotide sequence data reported are available in the DDBJ/EMBL/GenBank databases under the accession numbers AB174769, AB174770, AB174771, AB174772, and AB174773, respectively. Dots denote sequence identities and dashes indicate gaps introduced for maximal alignment. The nucleotide sequence numbers show the corresponding positions of those from the registered Lutzomyia species Lu. geniculata, Lu. longipalpis, Lu. nunez-tovari anglesi, Lu. toroensis, Lu. vattieri, and Lu. verrucarum. The Afa I site is shown in the box. 
TABLE 1

Detection of natural Leishmania infection in Ecuador within individual sand flies by polymerase chain reaction (PCR) or by microscopic examination

\begin{tabular}{lccccc}
\hline & \multicolumn{2}{c}{ PCR } & & \multicolumn{2}{c}{ Microscopic examination } \\
\cline { 2 - 3 } \cline { 5 - 6 } Locality & $\begin{array}{c}\text { No. } \\
\text { examined }\end{array}$ & $\begin{array}{c}\text { No. } \\
\text { infected (\%) }\end{array}$ & & $\begin{array}{c}\text { No. } \\
\text { examined }\end{array}$ & $\begin{array}{c}\text { No. } \\
\text { infected (\%) }\end{array}$ \\
\hline Chanchan & 115 & $2(1.7 \%)$ & & 105 & $2(1.9 \%)$ \\
Alausi & 68 & $4(5.9 \%)$ & & 38 & $3(7.9 \%)$ \\
\hline
\end{tabular}

DNA fragments were confirmed to be the minicircle kinetoplast DNAs by PCR-Southern blotting analysis using the $L$. (L.) mexicana minicircle kinetoplast DNA probe and/or by nucleotide sequencing of the PCR products.

Classification of sand fly species. Since the classification of sand fly species based on morphology requires considerable expertise, we attempted to apply molecular biologic methods for this purpose. During the sequence analyses of sand fly $18 \mathrm{~S}$ rRNA genes, we found that PCR fragments from $L u$. ayacuchensis, but not those from Lu. hartmanni, Lu. trapidoi, Lu. panamensis, and Lu. gomezi, have a digestion site (GT/ AC) for the restriction enzyme Afa I at nucleotides 297-300 (Figure 2). Thus, the PCR fragments from Lu. ayacuchensis, but not other species of sand flies, were expected to be cut into 137- and 268-basepair fragments with this enzyme. The enzyme $A f a$ I cut all 18S rRNA gene fragments from Leishmania-positive sand flies (Figure 4, lanes 1-6) as well as those from $\mathrm{Lu}$. ayacuchensis (Figure 4, lanes 7), but not those from any other species captured in lowland subtropical areas of Ecuador for the separate experiment (Figure 4, lanes 8-11). Furthermore, nucleotide sequence analyses of these fragments were carried out and the sequences from Leishmaniapositive sand flies were all identical with those from $L u$. ayacuchensis. These results indicated that the Leishmania-

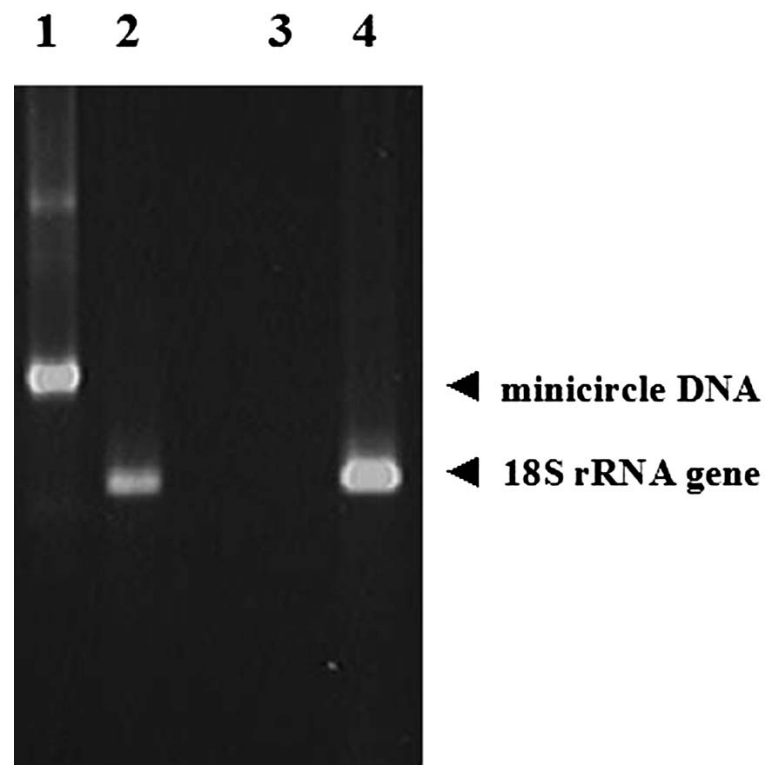

FIGURE 3. Detection of Leishmania minicircle kinetoplast DNA within a microscopically ascertained Leishmania-positive (lane 1) or -negative (lane 3 ) sand fly by a polymerase chain reaction. The $L u t$ zomyia $18 \mathrm{~S}$ ribosomal RNA (rRNA) gene was also amplified in these samples (lane 2 and 4 , respectively).

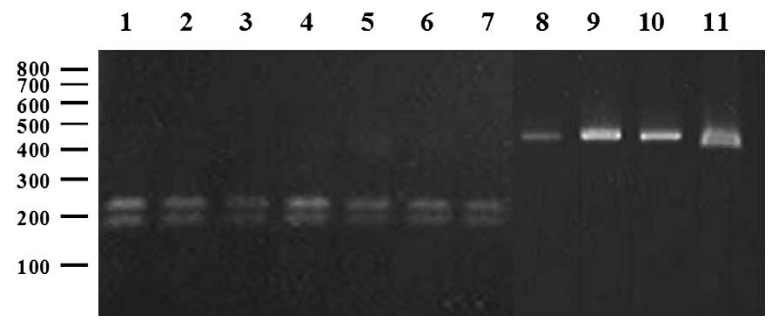

FIGURE 4. Digestion of $18 \mathrm{~S}$ ribosomal RNA (rRNA) gene fragments from sand flies with the restriction enzyme $A f a$ I. Partial fragments of 18S rRNA genes from sand flies were amplified by a polymerase chain reaction and the products were then digested with $A f a$ I. DNA samples from minicircle DNA-positive sand flies captured at Chanchan [CC-Lu.97 (lane 1) and CC-Lu.103 (lane 2)] and Alausi [AL-Lu.24 (lane 3), AL-Lu.44 (lane 4), AL-Lu.51 (lane 5), and AL-Lu.54 (lane 6)], Lu. ayacuchensis (lane 7), Lu. hartmanni (lane 8), Lu. trapidoi (lane 9), Lu. Panamensis (lane 10), and Lu. gomezi (lane 11) were used as templates. The numbers on the left are in basepairs.

positive sand flies captured in this study were all $L u$. ayacuchensis, corresponding to our previous findings. ${ }^{28}$

Identification of Leishmania species by analysis of the $\boldsymbol{C y t}$ $\boldsymbol{b}$ gene. In the next step, we identified the Leishmania species detected within individual sand flies by using a recently established method to analyze the Leishmania Cyt b gene. ${ }^{31}$ Thirty cycles of PCR amplification, which was the same number used for the detection of Leishmania minicircle kinetoplast DNA, were performed with $C y t$ b gene-specific primers, and the PCR products were subjected to electrophoresis. The result showed that four of six Leishmania minicircle kinetoplast DNA-positive samples were positive for Leishmania the $C y t$ b gene (Figure 5). Furthermore, we performed 40 cycles of the PCR with these primers to obtain a more sensitive
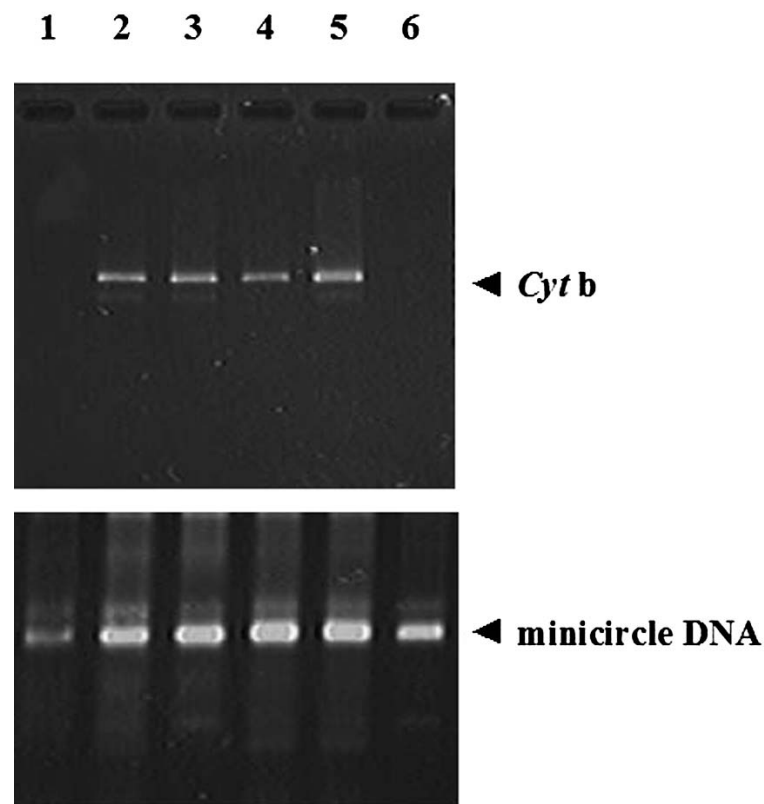

FIGURE 5. Thirty cycles of polymerase chain reaction amplification with Leishmania cytochrome $b(C y t \mathrm{~b})$-specific primers. DNA samples from minicircle DNA-positive sand flies captured at Chanchan [CC-Lu.97 (lane 1) and CC-Lu.103 (lane 2)] and Alausi [AL-Lu.24 (lane 3), AL-Lu.44 (lane 4), AL-Lu.51 (lane 5), and AL-Lu.54 (lane $6)$ ] were used as templates. 
result; one sample was positive and the rest were negative in this assay. Nucleotide sequence analyses of these DNA fragments were performed and their sequences showed the highest homology with the $C y t$ b gene of $L$. (L.) mexicana (98.4$98.5 \%$ ) when compared with those of other species (88.7-96.9\%). Thus, the parasites detected within individual sand flies caught in Chanchan and Alausi were all $L$. (L.) mexicana. This result was consistent with our previous findings that the Andean-type cutaneous leishmaniasis observed in these areas was caused by $L$. (L.) mexicana. ${ }^{29}$

\section{DISCUSSION}

In the present study, we established a sensitive method for detecting Leishmania protozoa by PCR using primers specific for Leishmania minicircle kinetoplast DNA and detected Leishmania organisms within naturally infected individual sand flies. Furthermore, we showed that these Leishmaniapositive sand flies were all $\mathrm{Lu}$. ayacuchensis by analyzing their 18S rRNA gene fragments. We also attempted to identify the Leishmania species within infected sand flies by an analysis of their $C y t$ b gene sequences and successfully identified five of six minicircle DNA-positive samples.

To determine successful DNA extraction from each sand fly, we designed primers specific for the Lutzomyia $18 \mathrm{~S}$ rRNA gene and performed PCR amplification since this gene is well conserved among species and the sequences were available for six Lutzomyia species: Lu. geniculata, Lu. longipalpis, Lu. nunez-tovari anglesi, Lu. toroensis, Lu. vattieri, and $L u$. verrucarum. As templates, we used DNA samples from $L u$. hartmanni, Lu. trapidoi, Lu. panamensis, and $L u$. gomezi, as well as Lu. ayacuchensis, to see if we could detect $18 \mathrm{~S}$ rRNA genes in a variety of species. The sequence analyses of amplified DNA showed that all fragments contained parts of $18 \mathrm{~S}$ rRNA genes, indicating that the primers designed in this study were specific for at least 11 Lutzomyia species in the amplification of $18 \mathrm{~S}$ rRNA genes. Furthermore, we searched 18S rRNA gene sequences of the Old World (Phlebotomus $^{32,33}$ ) sand flies and found that these primers also reacted with the counterparts of all 10 species. These results strongly suggested that these sequences were conserved among species in both Lutzomyia and Phlebotomus, and the primers designed can be used as a positive control for DNA extraction in all species of sand flies.

Currently, sand fly species are identified principally based on their morphologic characteristics, mainly internal structures, such as spermatheca, cibarium, and pharynx in females and terminal genitalia in males. This method requires refined storage conditions for samples, a highly skilled technique, and taxonomic expertise. Recently, a molecular biologic technique was used to study the systematics and evolution of sand flies in the Old World, and a method for typing phlebotomine sand flies by use of a PCR and restriction enzyme digestion of the $18 \mathrm{~S}$ rRNA gene was reported. ${ }^{32}$ Thus, molecular biologic methods will be a powerful tool in sand fly taxonomy in the near future. In this study, we analyzed 18S rRNA gene sequences from five sand fly species including a unique species in Andean regions ( $\mathrm{Lu}$. ayacuchensis) and found a unique site of digestion with the restriction enzyme $A f a \mathrm{I}$ in the sequences from $L u$. ayacuchensis. We carried out Afa I digestion of PCR-amplified 18S rRNA gene fragments and showed that the enzyme cut all fragments from Leishmania-positive sand flies, as well as from Lu. ayacuchensis, but not those from any other species captured in this study. Furthermore, nucleotide sequences of the fragments from Leishmaniapositive sand flies were all identical with those from $L u$. $a y$ acuchensis, indicating that the Leishmania-positive sand flies captured in this study were all Lu. ayacuchensis. These results suggested that $A f a$ I digestion analysis of PCR-amplified $18 \mathrm{~S}$ rRNA fragments is helpful in confirming the identity of species such as Lu. ayacuchensis, at least in these Andean areas. Further investigations are required for the practical use of this sand fly typing method for taxonomy; however, it may be possible in the near future to classify sand fly species in the New World by modifying this method, even though many more species exist in the New World than in the Old World. ${ }^{3}$

In this study, we could detect Leishmania DNA equivalent to $0.1-1$ parasites in all species by the PCR protocol, although the sensitivity was somewhat different among species. The difference in the size of amplified fragments among species may reflect the size of the dominant minicircle kinetoplast DNA in the strain since such DNA varies between 0.75 and 1 kilobasepairs in length. ${ }^{19,34-36}$ Each DNA sample extracted from individual sand flies was resuspended in $10 \mu \mathrm{L}$ of distilled water and $1-\mu \mathrm{L}$ portions of these extracts were used for PCR amplification. Thus, we can detect Leishmania if each sand fly is infected with 1-10 parasites. This sensitivity is high enough to detect Leishmania promastigotes within individual sand flies. We applied this method to the detection of Leishmania protozoa from individual ethanol-fixed sand flies captured in Andean areas where Andean-type cutaneous leishmaniasis is endemic. ${ }^{26,29}$ The results were comparable with those obtained by the microscopic examination of dissected flies, indicating that this method is practical for monitoring the Leishmania infection rate of sand flies in endemic areas. The advantages of this method are as follows; 1) the sensitivity is high, 2) not only fresh samples but also ethanol-fixed ones are available, 3) no special skills or expertise are required, and 4) a large number of specimens can be processed with limited effort. Recently, Leishmania species within sand flies were reported to be detected and identified by a two-step PCR method targeting minicircle kinetoplast DNA in the Old World. ${ }^{23}$ Minicircle DNAs have been generally used as a target gene for the identification of Leishmania species by molecular biologic methods, although they have variations in their sequences. ${ }^{19,34-36}$ More recently, the sequences of $C y t \mathrm{~b}$ genes from various Leishmania species were assessed and shown to be a very good standard for determination of the species. ${ }^{31}$ In the present study, we successfully identified the Leishmania species in five of six minicircle DNA-positive samples using this newly established method. The copy numbers of maxicircle DNA encoding $C y t \mathrm{~b}$ and minicircle DNA per parasite are reported to be 20-50 and approximately 10,000 , respectively, ${ }^{37}$ and the different sensitivities of PCR amplification between minicircle DNA and the $C y t \mathrm{~b}$ gene may reflect mainly the amount of target DNA per parasite. Further studies on the development of a nested-PCR method may solve this problem. Thus, the method established in this study, which detects Leishmania minicircle kinetoplast DNA and identifies the species through an analysis of $C y t$ b gene sequences, may be the best way to detect and identify Leishmania within individual sand flies using a molecular biologic technique. 
In conclusion, we detected and identified Leishmania protozoa within naturally infected individual sand flies using PCR- and DNA sequencing-based methods. In addition, we showed that Leishmania-positive sand flies were all $L u$. ayacuchensis by analyzing their $18 \mathrm{~S}$ rRNA gene fragments. This method is relatively easy to perform and can process a large number of samples with limited effort when compared with conventional microscopic examination after dissection. Thus, it will be a powerful tool not only for monitoring the Leishmania infection rate in sand fly populations, but also for the rapid identification of both prevalent Leishmania and sand fly species in endemic areas.

Received April 28, 2004. Accepted for publication August 26, 2004.

Acknowledgments: We are indebted to Roberto Sud for technical assistance throughout the study; Dr. Ernesto Gutierrez (Minister of Health, Guayaquil, Ecuador) and Dr. Luiggi Martini R. (ViceMinister of Health, Guayaquil, Ecuador) for coordinating our field activities; and to Drs. Teresa Flor, Jenny Rodriguez, and Yim-Yan Wong Chum (National Institute of Health and Tropical Medicine, Guayaquil, Ecuador) for their support during the laboratory phase of the study.

Financial support: This study was supported by the Ministry of Education, Science, Culture and Sports of Japan (grant no. 10037385, 15590371).

Authors' addresses: Hirotomo Kato and Hiroyuki Iwata, Department of Veterinary Hygiene, Faculty of Agriculture, Yamaguchi University, 1677-1 Yoshida, Yamaguchi 753-8515, Japan. Hiroshi Uezato and Shigeo Nonaka, Department of Dermatology, Faculty of Medicine, University of the Ryukyus, Nishihara, Okinawa 903-0215, Japan. Ken Katakura, Department of Disease Control, Graduate School of Veterinary Medicine, Hokkaido University, Kita 18 Nishi 9, Kita-ku, Sapporo 060-0818, Japan. Manuel Calvopiña, Jorge D. Marco, Paola A. Barroso, Masataka Korenaga, and Yoshihisa Hashiguchi, Department of Parasitology, Kochi Medical School, Kochi University, Nankoku, Kochi 783-8505, Japan. Eduardo A. Gomez, Departamento de Medicina Tropical, Facultad de Medicina, Universidad Catolica de Guayaquil, PO Box 10833, Guayaquil, Ecuador. Tatsuyuki Mimori, Department of Tumor Genetics and Biology, Graduate School of Medical Science, Kumamoto University, Kumamoto 860-0811, Japan.

Reprint requests: Hirotomo Kato, Department of Veterinary Hygiene, Faculty of Agriculture, Yamaguchi University, 1677-1 Yoshida, Yamaguchi 753-8515, Japan Telephone: 81-83-933-5900, Fax: 81-83933-5899, E-mail: katoh@yamaguchi-u.ac.jp.

\section{REFERENCES}

1. Desjeux P, 1996. Leishmaniasis. Public health aspects and control. Clin Dermatol 14: 417-423.

2. Choi CM, Lerner EA, 2001. Leishmaniasis as an emerging infection. J Invest Dermatol Symp Proc 6: 175-182.

3. Killick-Kendrick R, 1999. The biology and control of phlebotomine sand flies. Clin Dermatol 17: 279-289.

4. Kreutzer RD, Souraty N, Semko ME, 1987. Biochemical identities and differences among Leishmania species and subspecies. Am J Trop Med Hyg 36: 22-32.

5. Grimaldi G Jr, David JR, McMahon-Pratt D, 1987. Identification and distribution of New World Leishmania species characterized by serodeme analysis using monoclonal antibodies. Am J Trop Med Hyg 36: 270-287.

6. Mimori T, Grimaldi G Jr, Kreutzer RD, Gomez EA, McMahonPratt D, Tesh RB, Hashiguchi Y, 1989. Identification, using isoenzyme electrophoresis and monoclonal antibodies, of Leishmania isolated from humans and wild animals of Ecuador. Am J Trop Med Hyg 40: 154-158.

7. Barker DC, 1989. Molecular approaches to DNA diagnosis. Parasitology 99: S125-S146.
8. Katakura K, Matsumoto Y, Gomez EA, Furuya M, Hashiguchi Y, 1993. Molecular karyotype characterization of Leishmania panamensis, Leishmania mexicana, and Leishmania major-like parasites: agents of cutaneous leishmaniasis in Ecuador. Am J Trop Med Hyg 48: 707-715.

9. de Brujin MH, Labrada LA, Smyth AJ, Santrich C, Barker DC, 1993. A comparative study of diagnosis by the polymerase chain reaction and by current clinical methods using biopsies from Colombian patients with suspected leishmaniasis. Trop Med Parasitol 44: 201-207.

10. Ashford DA, Bozza M, Freire M, Miranda JC, Sherlock I, Eulalio C, Lopes U, Fernandes O, Degrave W, Barker RH Jr, Badaró R, David JR, 1995. Comparison of the polymerase chain reaction and serology for the detection of canine visceral leishmaniasis. Am J Trop Med Hyg 53: 251-255.

11. Laskay T, Miko TL, Negesse Y, Solbach W, Rollinghoff M, Frommel D, 1995. Detection of cutaneous Leishmania infection in paraffin-embedded skin biopsies using the polymerase chain reaction. Trans $R$ Soc Trop Med Hyg 89: 273-275.

12. Mathis A, Deplazes P, 1995. PCR and in vitro cultivation for detection of Leishmania spp. in diagnostic samples from humans and dogs. J Clin Microbiol 33: 1145-1149.

13. Andresen K, Gaafar A, El-Hassan AM, Ismail A, Dafalla M, Theander TG, Kharazmi A, 1996. Evaluation of the polymerase chain reaction in the diagnosis of cutaneous leishmaniasis due to Leishmania major: a comparison with direct microscopy of smears and sections from lesions. Trans $R$ Soc Trop Med Hyg 90: 133-135.

14. Mimori T, Sasaki J, Nakata M, Gomez EA, Uezato H, Nonaka S, Hashiguchi Y, Furuya M, Saya H, 1998. Rapid identification of Leishmania species from formalin-fixed biopsy samples by polymorphism-specific polymerase chain reaction. Gene 210: 179-186.

15. Uezato H, Hagiwara $\mathrm{K}$, Hosokawa A, Maruno M, Nonaka S, Oshiro M, Furuya M, Gomez EA, Hashiguchi Y, 1998. A preliminary study aimed at the detection of Leishmania parasites in subjects with cutaneous leishmaniasis using polymerase chain reaction. J Dermatol 25: 290-298.

16. Uezato H, Hagiwara K, Hosokawa A, Maruno M, Nonaka S, Oshiro M, Nakashima Y, Furuya M, Hashiguchi Y, 1998. Comparative studies of the detection rates of Leishmania parasites from formalin, ethanol-fixed, frozen human skin specimens by polymerase chain reaction and Southern blotting. J Dermatol 25: 623-631.

17. Katakura K, Kawazu SI, Sanjyoba C, Naya T, Matsumoto Y, Ito M, Nagakura K, Aikawa M, Hashiguchi Y, 1998. Leishmania mini-exon genes for molecular epidemiology of leishmaniasis in China and Ecuador. Tokai J Exp Clin Med 23: 393-399.

18. Matsumoto T, Hashiguchi Y, Gomez EA, Calvopiña MH, Nonaka S, Saya H, Mimori T, 1999. Comparison of PCR results using scrape/exudate, syringe-sucked fluid and biopsy samples for diagnosis of cutaneous leishmaniasis in Ecuador. Trans R Soc Trop Med Hyg 93: 606-607.

19. Breniere SF, Telleria J, Bosseno MF, Buitrago R, Bastrenta B, Cuny G, Banuls AL, Brewster S, Barker DC, 1999. Polymerase chain reaction-based identification of New World Leishmania species complexes by specific kDNA probes. Acta Trop 73: 283-293.

20. Reithinger R, Lambson BE, Barker DC, Davies CR, 2000. Use of PCR to detect Leishmania (Viannia) spp. in dog blood and bone marrow. J Clin Microbiol 38: 748-751.

21. Reithinger R, Quinnell RJ, Alexander B, Davies CR, 2002. Rapid detection of Leishmania infantum infection in dogs: comparative study using an immunochromatographic dipstick test, enzyme-linked immunosorbent assay, and PCR. J Clin Microbiol 40: 2352-2356.

22. Mimori T, Matsumoto T, Calvopiña MH, Gomez EA, Saya H, Katakura K, Nonaka S, Shamsuzzaman SM, Hashiguchi Y, 2002. Usefulness of sampling with cotton swab for PCR-diagnosis of cutaneous leishmaniasis in the New World. Acta Trop 81: 197-202.

23. Aransay AM, Scoulica E, Tselentis Y, 2000. Detection and identification of Leishmania DNA within naturally infected sand flies by seminested PCR on minicircle kinetoplast DNA. Appl Environ Microbiol 66: 1933-1938. 
24. Hashiguchi Y, Gomez EA, de Coronel VV, Mimori T, Kawabata M, 1985. Leishmania isolated from wild mammals caught in endemic areas of leishmaniasis in Ecuador. Trans $R$ Soc Trop Med Hyg 79: 120-121.

25. Hashiguchi Y, Gomez EA, de Coronel VV, Mimori T, Kawabata M, 1985. Natural infections with promastigotes in man-biting species of sand flies in leishmaniasis-endemic areas of Ecuador. Am J Trop Med Hyg 34: 440-446.

26. Hashiguchi Y, Gomez EA, 1991. A review of leishmaniasis in Ecuador. Bull Pan Am Health Organ 25: 64-76.

27. Hashiguchi Y, 2003. Leishmaniasis. Otsuru M, Kamegai S, Hayashi S, eds. Progress of Medical Parasitology in Japan. Tokyo: Megro Parasitological Museum, 537-553.

28. Takaoka H, Gomez EA, Alexander JB, Hashiguchi Y, 1990. Natural infections with Leishmania promastigotes in Lutzomyia ayacuchensis (Diptera: Psychodidae) in an Andean focus of Ecuador. J Med Entomol 27: 701-702.

29. Hashiguchi Y, Gomez EA, de Coronel VV, Mimori T, Kawabata M, Furuya M, Nonaka S, Takaoka H, Alexander JB, Quizhpe AM, Grimaldi G Jr, Kreutzer RD, Tesh RB, 1991. Andean leishmaniasis in Ecuador caused by infection with Leishmania mexicana and L. major-like parasites. Am J Trop Med Hyg 44. 205-217.

30. Gomez EA, Hashiguchi Y, 1991. Monthly variation in natural infection of the sandfly Lutzomyia ayacuchensis with Leishmania mexicana in an endemic focus in the Ecuadorian Andes. Ann Trop Med Parasitol 85: 407-411.
31. Luyo-Acero G, Uezato H, Oshiro M, Kariya K, Katakura K, Gomez EAL, Hashiguchi Y, Nonaka S, 2004. Sequence variation of the Cytochrome $b$ gene of various human patholgenic members of the genus Leishmania: a new approach for their identification. Parasitology 128: 483-491.

32. Aransay AM, Scoulica E, Chaniotis B, Tselentis Y, 1999. Typing of sandflies from Greece and Cyprus by DNA polymorphism of 18S rRNA gene. Insect Mol Biol 8: 179-184.

33. Aransay AM, Scoulica E, Tselentis Y, Ready PD, 2000b. Phylogenetic relationships of phlebotomine sandflies inferred from small subunit nuclear ribosomal DNA. Insect Mol Biol 9: 157168.

34. Rogers WO, Wirth DF, 1988. Generation of sequence diversity in the kinetoplast DNA minicircles of Leishmania mexicana amazonensis. Mol Biochem Parasitol 30: 1-8.

35. Noyes HA, Reyburn H, Bailey JW, Smith D, 1998. A nestedPCR-based schizodeme method for identifying Leishmania kinetoplast minicircle classes directly from clinical samples and its application to the study of the epidemiology of Leishmania tropica in Pakistan. J Clin Microbiol 36: 2877-2881.

36. Brewster S, Barker DC, 2002. Analysis of minicircle classes in Leishmania (Viannia) species. Trans R Soc Trop Med Hyg 96 S55-S63.

37. Simpson L, 1986. Kinetoplast DNA in trypanosomid flagellates. Int Rev Cytol 99: 119-179. 